\title{
MONITORING SPATIAL PATTERNS OF VEGETATION PHENOLOGY IN AN AUSTRALIAN TROPICAL TRANSECT USING MODIS EVI
}

\author{
Xuanlong Ma ${ }^{\mathrm{a}, \mathrm{b}}$ ，Alfredo Huete ${ }^{\mathrm{a}, *}$, Qiang Yu ${ }^{\mathrm{a}, \mathrm{b}}$ ，Kevin Davies ${ }^{\mathrm{a}}$, and Natalia Restrepo Coupe ${ }^{\mathrm{a}}$ \\ ${ }^{\text {a }}$ Plant Functional Biology and Climate Change Cluster, University of Technology, Sydney, Australia \\ ${ }^{\mathrm{b}}$ Institute of Geographic Sciences and Natural Resources Research, Chinese Academy of Sciences, Beijing, China
}

Commission VIII/6

KEY WORDS: NATT, tropical savannas, phenology, climate change, MODIS, EVI

\begin{abstract}
:
Phenology is receiving increasing interest in the area of climate change and vegetation adaptation to climate. The phenology of a landscape can be used as a key parameter in land surface models and dynamic global vegetation models to more accurately simulate carbon, water and energy exchanges between land cover and atmosphere. However, the characterisation of phenology is lacking in tropical savannas which cover more than $30 \%$ of global land area, and are highly vulnerable to climate change. The objective of this study is to investigate the spatial pattern of vegetation phenology along the Northern Australia Tropical Transect (NATT) where the major biomes are wet and dry tropical savannas. For this analysis we used more than 11 years Moderate Resolution Imaging Spectroradiometer (MODIS) Enhanced Vegetation Index (EVI) product from 2000 to 2011. Eight phenological metrics were derived: Start of Season (SOS), End of Season (EOS), Length of Season (LOS), Maximum EVI (MaxG), Minimum EVI (MinG), annual amplitude (AMP), large integral (LIG), and small integral (SIG) were generated for each year and each pixel. Our results showed there are significant spatial patterns and considerable interannual variations of vegetation phenology along the NATT study area. Generally speaking, vegetation growing season started and ended earlier in the north, and started and ended later in the south, resulting in a southward decrease of growing season length (LOS). Vegetation productivity, which was represented by annual integral EVI (LIG), showed a significant descending trend from the northern part of NATT to the southern part. Segmented regression analysis showed that there exists a distinguishable breakpoint along the latitudinal gradient, at least in terms of annual minimum EVI (EVI), which is located between $18.84^{\circ} \mathrm{S}$ to $20.04^{\circ} \mathrm{S}$.
\end{abstract}

\section{INTRODUCTION}

Phenology as a subject to study the life cycles of vegetation and the interactions between vegetation and climate (White and Thornton, 1997) is receiving increasing interests in global change research. Vegetation phenology can be used as a key parameter in large scale ecosystem simulation models (Running and Hunt, 1993) and general circulation models (Sellers et al., 1996). At the same time, vegetation phenology is also an accurate indicator of influences by climate change on vegetation growth (Menzel et al., 2006).

Phenological studies of vegetation traditionally utilised ground based techniques (Jeffree, 1960, Sparks and Jeffree, 2000), however, increasing number of studies utilise remote sensing to study vegetation phenology on a large scale (Schwartz, 1999, Zhang et al., 2003, Stöckli, 2004). Compared with field based cameras or visual inspection, space borne optical sensors such as MERIS (MEdium Resolution Imaging Spectrometer) and MODIS (Moderate Resolution Imaging Spectroradiometer) are able to provide daily measurements of variety biophysical and biochemical information of the earth's surface with moderate spatial resolution.

${ }^{*}$ Corresponding address: Plant functional biology and climate change cluster, University of Technology, Sydney, PO Box 123, Broadway, NSW, 2000, Australia, Tel: +61 29514 4084, Email: alfredo.huete@uts.edu.au
However, till now most remote sensing phenology studies focused on temperature and light limited systems (Beurs and Henebry, 2010), with few conducted on water limited systems (Brown and de Beurs, 2008), and rarely on tropical savannas. Tropical savannas are generally defined as a biome with discrete tree stratum and continuous grassy ground layer (Frost et al., 1986), which covers one-sixth of the global land surface, and contributes approximately $30 \%$ of the gross primary productivity (GPP) of all terrestrial ecosystems (House and Hall, 2001). Tropical savannas are also considered particularly vulnerable to climate change (Canadell et al., 2003). Despite the importance of tropical savannas, studies of its vegetation phenology are lacking regardless of the methods, thus restricting our capability to understand the impact of possible climate change scenarios on tropical savannas ecosystems.

Previous studies showed that a biogeographical boundary existed in the NATT area, which may distributed around $16-20^{\circ} \mathrm{S} .18-20^{\circ} \mathrm{S}$ was considered as the south limit of the influences from monsoonal rainfall (Bowman, 1996, Burbidge, 1960), $15-16{ }^{\circ} \mathrm{S}$ was considered as the southern limit of wet season as well as the southern limit of monsoon tall-grass savannas (Cook and Heerdegen, 2001). Meanwhile, in terms of vegetation family and species, the major changes occur around $16-17^{\circ} \mathrm{S}$ (Egan and Williams, 1996). Based on these findings, we hypothesised that, if such a virtual biogeographical 
boundary exists, it might be reflected by vegetation phenology.

In this study, we mainly focused on two points: 1) using remote sensing to investigate the spatial patterns of vegetation phenology in the NATT area; 2) try to identify the abrupt change (breakpoint) in terms of the phenological metrics along the latitude in the NATT, thus providing a phenological perspective on the biogeographical boundary question. Our study showed that there were significant spatial patterns of vegetation phenology in the NATT during past decades, a north-south directional trend was identified. Meanwhile, breakpoint analysis showed that, there was a distinguishable 'breakpoint' located around $18^{\circ} \mathrm{S}$ to $20^{\circ} \mathrm{S}$,

\section{DATA AND METHODS}

\subsection{Study area}

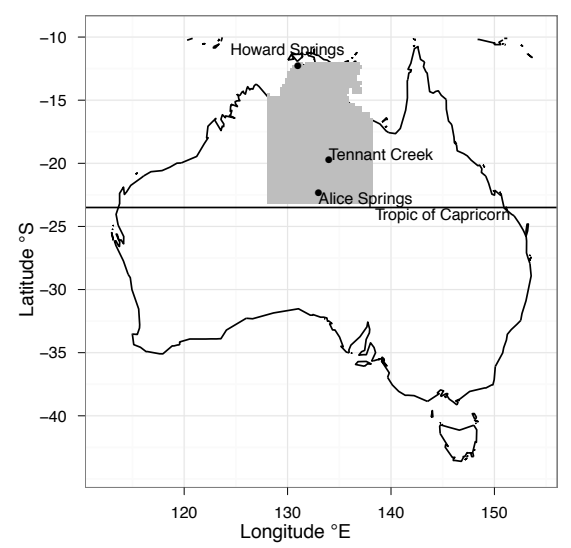

Figure 1: The spatial extent of the NATT study area (gray colour area)

This study focussed on Northern Australia Tropical Transect which was extended in this study as a 1.38 million $\mathrm{km}^{2}$ area which located between latitude $12^{\circ} \mathrm{S}$ and $23^{\circ}$ $\mathrm{S}$ and between longitude $128^{\circ} \mathrm{E}$ and $138^{\circ} \mathrm{E}$ (Fig. 1). The use of transects has been largely adopted by global change community over past two decades as a standard method to assess spatial patterns of biogeochemical processes (Koch et al., 1995). The spatial variation of long time constants along the transect can be used as an surrogate of predicted temporal variation to understand the future responses to global change (Koch et al., 1995). The Northern Australian Tropical Transect (NATT) was established under IGBP (International Geosphere Biosphere Programme) in the mid 1990s, and is one of three transects around world to study global savannas (Koch et al., 1995). Along the NATT, mean annual precipitation decreases from nearly $1700 \mathrm{~mm}$ in the north wet end (Howard Springs) to $300 \mathrm{~mm}$ in the south dry end (Alice Springs) (Hutley et al., 2011). The vegetation in NATT is a wet-dry savannas gradient where in northern half of NATT, the dominant vegetation is tropical savannas covered by overstory evergreen Eucalyptus and understory annual and perennial C4 grasses (Egan and Williams,
1996). However, in southern half of the NATT the dominance of savannas declines, and the dominance of Acacia woodlands and shrub lands and hummock grasslands increases. (Bowman and Connors, 1996).

\subsection{Data}

2.2.1 MOD13C1 EVI A total of more than 11 years (2000-2011) of MODIS Terra 16-day $0.05^{\circ}$ spatial resolution collection 5 vegetation indices product (MOD13C1) were used in this study. This product is mainly designed to provide globally consistent vegetation conditions (Running et al., 1994, Justice and Vermote, 1998). In this study, the Enhanced Vegetation Index (EVI) was used as a surrogate for vegetation growth condition. EVI can effectively reduce the soil background and atmospheric noise while improving the sensitivity in high biomass regions (Huete et al., 2002). The equation of EVI is:

$$
\mathrm{EVI}=2.5 \times \frac{\rho_{\text {nir }}-\rho_{\text {red }}}{\rho_{\text {nir }}+6 \times \rho_{\text {red }}-7.5 \times \rho_{\text {blue }}+1}
$$

where $\rho_{\text {NIR }}, \rho_{\text {red }}$, and $\rho_{\text {blue }}$ are the wavelengths in the near infrared, red, and blue bands respectively (Huete et al., 2002).

The residual cloud and aerosol contamination in the original EVI time series were filtered out based on the quality assurance (QA) flags provided along with the MOD13C1 product.

For pixels without distinct seasonality, such as deserts and water-bodies, no phenology metrics were derived. QA filtered data was temporally gap filled by the average value of the six points before and after the gap. Remaining noise was removed by a Savitzky-Golay filter.

\subsection{Methods}

2.3.1 Phenological metrics retrieval method In this study, each increase (green-up) and decrease (browndown) during a growing season was reproduced by two separate four parameters logistic function:

$$
y=a+\frac{b-a}{1+\exp \left(\frac{c-t}{d}\right)}
$$

where, $a$ is the background EVI before or after growing season, $b$ is the maximum EVI during growing season, $c$ is the inflection point when the fitted curve reached the maximum rising or decreasing speed, $d$ is the scaling factor which determines the rate of increase or decrease of EVI at inflection point. The parameters were estimated based on nonlinear least squares criteria for each pixel and each phenological cycle during 2000-2011, a total of 11 growth cycles.

The phenological transition dates were determined based on the curvature change rate $K^{\prime}$ of the fitted curve followed Zhang's method (Zhang et al., 2003). Specifically, Start of Season (SOS) corresponded to the timing 
when $K^{\prime}$ reached first local maximum during the greenup period, and End of Season (EOS) corresponded to the time when $K^{\prime}$ reached last local minima during the brown-down period. These moments were considered as the transitions of vegetation growing from one linear stage to another (Zhang et al., 2003). The DOY (Day of Year) of SOS and EOS started from July 1 of each year. The length of season was calculated as the difference between SOS and EOS. Other phenological metrics were calculated using function fitted time series. Respectively, Maximum of Greenness (MaxG) and Minimum of Greenness (MinG) were maximum and minimum EVI values during a phenological cycle; amplitude (AMP) was the difference between MaxG and MinG; Large Integral of Greenness (LIG) was the daily integrated EVI value for a phenological cycle; Small Integral of Greenness (SIG) was the daily integrated EVI during growing season (defined as a period between SOS and EOS) subtracted daily integrated MinG during the same period.

2.3.2 Segmented regression to identify breakpoints in latitudinal gradients of phenological metrics In this study, segmented linear regression was used to identify the breakpoint for phenological index along the latitude. Segmented linear regression applies linear regression to $(x, y)$ data that do not have a linear relation (Wayne Skaggs, 1996). On the relations between phenological metrics and latitude, it is hypothesised that there might be a significant breakpoint existed, however, generally the relations do not necessarily have to be linear. So that with segmented linear regression, the breakpoints can be introduced, among different segments, separate linear regression are applied and by this means nonlinear relations between phenological metrics and latitude might be approximated by a series linear segments (Wayne Skaggs, 1996). By calculation of the confidence intervals of breakpoints, optimum breakpoint, which means that the breakpoint with smallest interval can be selected (Oosterbaan et al., 1990).

\section{RESULTS AND DISCUSSION}

\subsection{Spatial patterns of vegetation phenology}

In the NATT study area, all phenological metrics exhibited significant spatial patterns in terms of 11 years of average conditions (Fig. 2, 3,4, and 5). Over the NATT, the dates of vegetation growing season onset (SOS) ranged from approximately late August to late January, spanning a five months time period. While the dates of vegetation growing season dormancy (EOS) ranged from late February to late October, spanning approximately an eight months time period. The length of vegetation growing season (LOS), which is the difference between EOS and SOS, ranged from about 138 days to 354 days, with differences as large as 216 days (7 months). Table 1 and Table 2 provide detailed statistical summary for all eight phenological metrics over the whole NATT study area.

The latitudinal gradients of vegetation phenology were also very significant in the NATT area. From north to
Table 1: Five-number summary 1 of phenological metrics in the NATT area. The phenological metrics were the average of 11 years.

\begin{tabular}{lcccc}
\hline & SOS & EOS & LOS & MaxG \\
\hline Minimum & 50 & 243 & 138 & 0.1048 \\
25\% quantile & 120 & 355 & 235 & 0.1794 \\
Median & 133 & 384 & 258 & 0.2395 \\
75\% quantile & 143 & 414 & 278 & 0.2921 \\
Maximum & 214 & 478 & 354 & 0.4902 \\
\hline
\end{tabular}

south, the dates of vegetation growing season onset significantly shifted to later by 3.916 days per latitude degree (Fig. 6(a)). While the dates of vegetation growing season dormancy also shifted south to later by approximately 1.75 days per latitude degree (Fig. 6(b)), however, the latitudinal trend of EOS was not as strong as the trend of SOS. The trends of SOS and EOS naturally led to the latitudinal trend of LOS (length of season), which showed a southward decreasing by approximately 1.6 days per latitude degree (Fig. 7(a)). The most significant latitudinal gradient came from LIG (integral of annual EVI), which can be considered as the vegetation annual productivity, showed a almost straight line decay, where the latitudinal averaged LIG in the south end of NATT was only approximately $38 \%$ of the north end (Fig. 7(b)).

In the temporal scale, the vegetation phenological metrics in the southern NATT generally had a relatively larger interannual variabilities than the northern NATT (the vertical lines in Fig. 6 and 7, which were the temporal standard deviations).

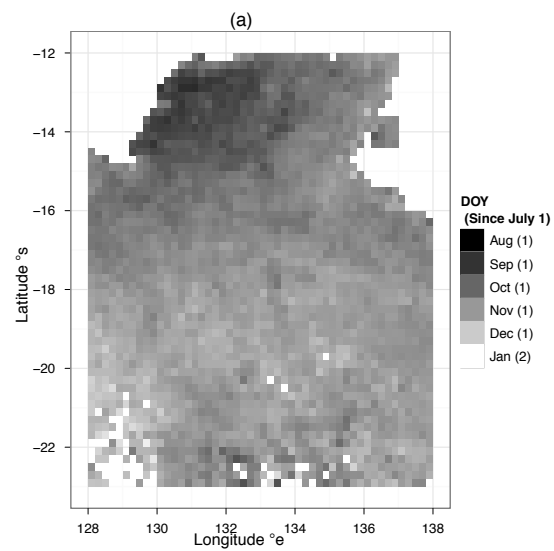

Figure 2: Spatial patterns of 11 years (2000-2011) mean SOS (the date of growing season onset) in the NATT.The numbers in the bracket indicate the calendar years, which 1 means first half of phenological year, i.e. from July 1 to December 31, 2 means second half of phenological year, i.e. from next January 1. Original 0.05 degree resolution result had been aggregated to 0.2 degree resolution for plotting purpose.

\subsection{Results of breakpoint analysis}

The breakpoint analysis showed that at least in terms of annual minimum EVI (MinG), which was considered as a good indicator of tree cover ratio, there was a detectable change around $18.84{ }^{\circ} \mathrm{S}$ and $20.02{ }^{\circ} \mathrm{S}$ (Fig. 8), 


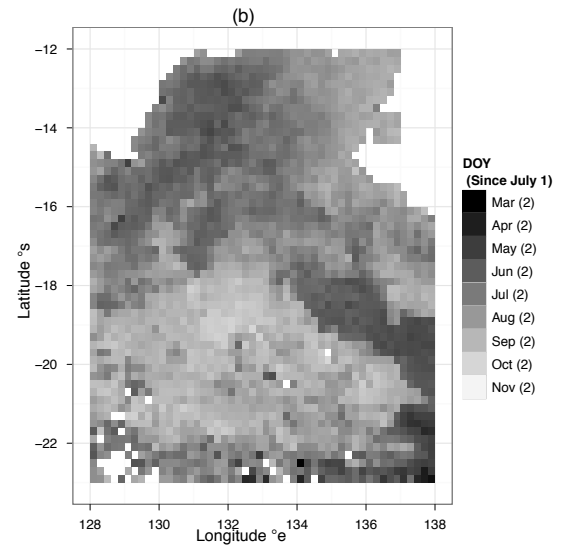

Figure 3: Spatial patterns of 11 years (2000-2011) mean EOS (the date of growing season end) in the NATT. The numbers in the bracket indicate the calendar years, which 1 means first half of phenological year, i.e. from July 1 to December 31, 2 means second half of phenological year, i.e. from next January 1. Original 0.05 degree resolution result had been aggregated to 0.2 degree resolution for plotting purpose.

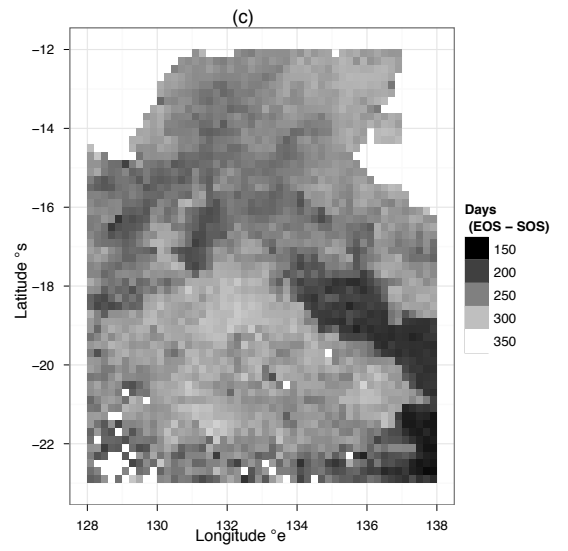

Figure 4: Spatial patterns of 11 years (2000-2011) mean LOS (the length of growing season) in the NATT. Original 0.05 degree resolution result had been aggregated to 0.2 degree resolution for plotting purpose.

and the breakpoint shifted its location inter annually in a approximately 1.18 degree extent (Fig. 8). In the north of this boundary, the annual minimum EVI dropped dramatically as a function of latitude, however, in the south of this boundary, the downward trend became gradually slowing (Fig. 8). In the south of this boundary, the minimum EVI was generally lower than 0.14 , even lower than 0.12 in some year and reached as low as 0.10 , which might be considered as soil background. And in the north end, the annual minimum EVI can be as large as 0.24 , approximately twofold than its southern counterpart (Fig. 8).

\section{DISCUSSION AND CONCLUSION}

This study has two significances:

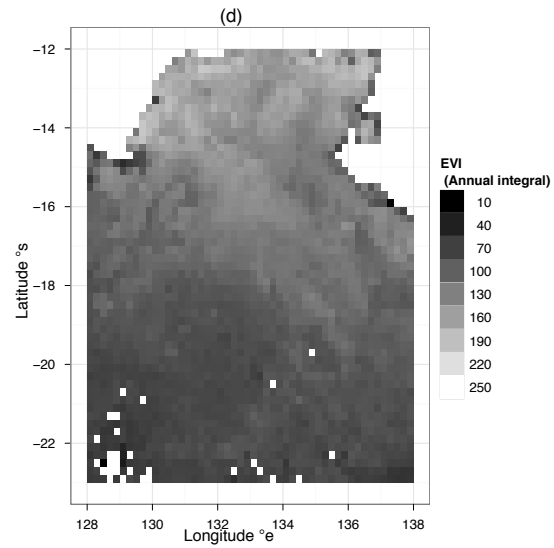

Figure 5: Spatial patterns of 11 years (2000-2011) mean LIG (the annual integral of EVI) in the NATT. Original 0.05 degree resolution result had been aggregated to 0.2 degree resolution for plotting purpose.

Table 2: Five-number summary 2 of phenological metrics in the NATT area. The phenological metrics were the average of 11 years.

\begin{tabular}{lcccc}
\hline & MinG & AMP & LIG & SIG \\
\hline Minimum & 0.0024 & 0.0053 & 2.87 & 2.19 \\
25\% quantile & 0.1222 & 0.0519 & 89.19 & 55.60 \\
Median & 0.1455 & 0.0824 & 110.50 & 75.11 \\
75\% quantile & 0.1779 & 0.1182 & 135.58 & 91.79 \\
Maximum & 0.3458 & 0.3003 & 248.74 & 148.08 \\
\hline
\end{tabular}
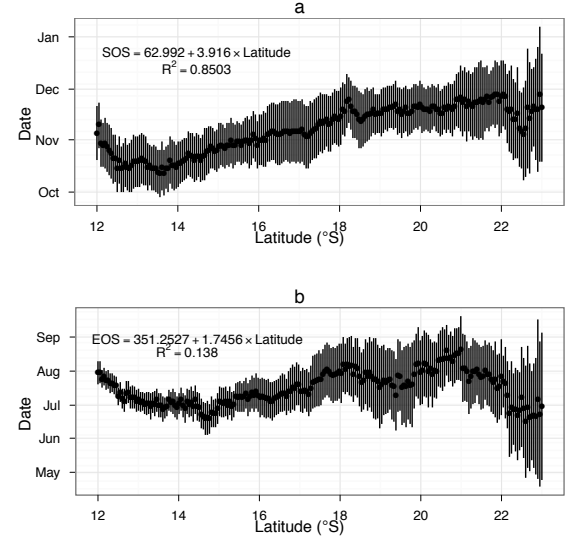

Figure 6: Latitudinal gradients of vegetation phenology along the transect (a) SOS; (b) EOS. The equations show the phenological metrics as a function of latitude. The vertical lines are the temporal standard deviations of these latitudinal gradients.

1. To our knowledge, this study was the first investigation of vegetation phenology using an almost an complete MODIS datasets for the NATT study area.

2. A 'breakpoint' was identified in this transect from a vegetation phenology perspective. 

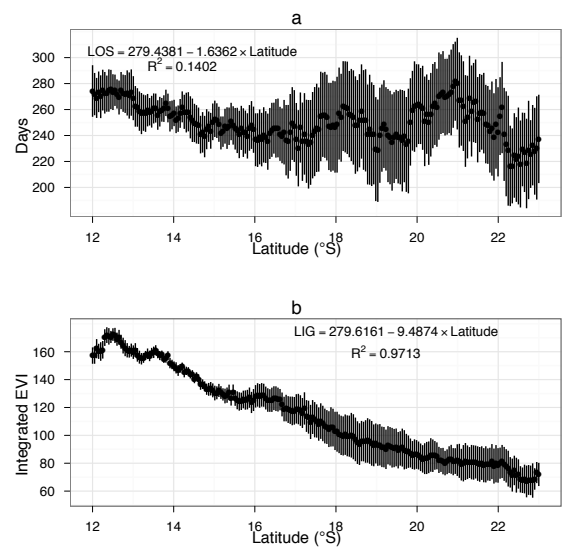

Figure 7: Latitudinal gradients of vegetation phenology along the transect (a) LOS; (b) LIG. The equations show the phenological metrics as a function of latitude. The vertical lines are the temporal standard deviations of these latitudinal gradients.

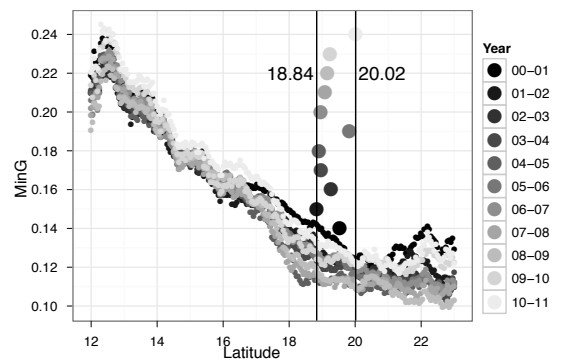

Figure 8: Spatial distributions and interannual variation of MinG breakpoints. Small points are interannual variations of annual minimum EVI along the latitude, large points are interannual variations of breakpoints. The north and south boundaries of these breakpoints are indicated by two vertical lines. The numbers give the actual latitudes of north and south boundary.

From an evolutionary point of view, the vegetation phenology is the result of biological adaption to historical climate. However, it is hard to study the variations of vegetation phenology in the time dimension over a short period. The assumption of using sub-continental scale transects to study global change problems is that the spatial variation can be used as a surrogate of the temporal variations (Koch et al., 1995). So that even if it is difficult to predict vegetation phenology in future, we do have the possibilities to derive the vegetation phenology under different climate change scenarios through the investigation in the spatial dimensions, which is more feasible (Cook and Heerdegen, 2001).

The southward decreasing trends of vegetation productivity (annual integral EVI) can be attributed to both internal and external factors. Internally, tree species richness are decreasing southward along NATT (Williams et al., 1996). Previous studies suggested that decreasing of woody richness always associates with decreasing of vegetation productivity (Waring et al., 2006, MacArthur, 1969). Externally, environmental factors , including pre- cipitation and soil water content, also have significant north-south decreasing trend in this area (Williams et al., 1996).

In the temporal scale, large interannual variations of vegetation phenology may suggest that the environmental factors, which control vegetation growth, should have corresponding interannual variations in this area. In the NATT, both precipitation amount and precipitation pattern have significant interannual variations (Cook and Heerdegen, 2001).

In this study we used annual minimum EVI, which is considered as an indicator of evergreen component, to investigate the spatial distribution of a biogeographical boundary in the NATT area. However, in addition to annual minimum EVI, we still have seven other phenological metrics available. This study suggested the potential to define the biogeographical boundary from a vegetation phenology perspective. Future research will attempt to identify this boundary using other phenological metrics.

In conclusion, this study characterized eight vegetation phenological metrics for a sub-continental tropical transect spanning the past 11 years. Our results showed that these metrics had significant spatial patterns as well as considerable interannual variations. However, the environmental control on these phenological patterns remains unclear, which requiring further investigations with the collaboration efforts from both remote sensing and climatological perspectives.

\section{ACKNOWLEDGEMENTS}

This research was partially support by ARC-(DP1115479) grant entitled "Integrating remote sensing, landscape flux measurements, and phenology to understand the impacts of climate change on Australian landscapes" (Huete, CI). The first author appreciates the financial support from Chinese Scholarship Council, which enables the first author to study abroad and focus on his research.

\section{REFERENCES}

Beurs, K. M. D. and Henebry, G. M., 2010. SpatioTemporal Statisticall Methods for Modelling Land Surface Phenology. Springer Netherlands, Dordrecht.

Bowman, D., 1996. Diversity Patterns of Woody Species on a Latitudinal Transect From the Monsoon Tropics to Desert in the Northern Territory, Australia. Australian Journal of Botany 44(5), pp. 571-580.

Bowman, D. M. J. S. and Connors, G. T., 1996. Does low temperature cause the dominance of Acacia on the central Australian mountains? Evidence from a latitudinal gradient from 11 o to 260 South in the Northern Territory, Australia. Journal of Biogeography 23(2), pp. 245-256.

Brown, M. E. and de Beurs, K. M., 2008. Evaluation of multi-sensor semi-arid crop season parameters based on NDVI and rainfall. Remote Sensing of Environment 112(5), pp. 2261-2271. 
Burbidge, N., 1960. The phytogeography of the australian region. Australian Journal of Botany 8(2), pp. 75-211.

Canadell, J. G., Dickinson, R., Hibbard, K., Raupach, M., Apps, M., Chedin, A., Chen, C.-T. A., Cox, P. M., Druffel, E. R. M., Field, C., Lankao, P. R., Lebell, L., Patwardhan, A., Sabine, C., Valentini, R., Yamagata, Y. and Young, O., 2003. Global Carbon Project The Science Framework and Implementation. Technical Report 1.

Cook, G. D. and Heerdegen, R. G., 2001. Spatial variation in the duration of the rainy season in monsoonal Australia. International Journal of Climatology 21(14), pp. 1723-1732.

Egan, J. L. and Williams, R. J., 1996. Lifeform distributions of woodland plant species along a moisture availability gradient in Australia's monsoonal tropics. Aust. Systematic Bot. 9(2), pp. 205-217.

Frost, P., Medina, E., Menaut, J.-C., Solbrig, O., Swift, M. and Walker, B., 1986. Responses of savannas to stress and disturbance: A proposal for collabrative programme of research. Biology International special is(10), pp. 81 .

House, J. I. and Hall, D. O., 2001. Productivity of Tropical Savannas and Grasslands. Terrestrial Global Productivity (16), pp. 363-400.

Huete, A., Didan, K., Miura, T., Rodriguez, E. P., Gao, X. and Ferreira, L. G., 2002. Overview of the radiometric and biophysical performance of the MODIS vegetation indices. Remote Sensing of Environment 83(1-2), pp. 195-213.

Hutley, L. B., BERINGER, J., Isaac, P. R., Hacker, J. M. and Cernusak, L. A., 2011. A sub-continental scale living laboratory: Spatial patterns of savanna vegetation over a rainfall gradient in northern Australia. Agricultural and Forest Meteorology pp. 1-12.

Jeffree, E. P., 1960. Some long-term means from the phenological reports (1891-1948) of the Royal Meteorological Society. Quarterly Journal of the Royal Meteorological Society 86(367), pp. 95-103.

Justice, C. O. and Vermote, E., 1998. The Moderate Resolution Imaging Spectroradiometer (MODIS): Land remote sensing for global change research. Geoscience and ....

Koch, G. W., Vitousek, P. M., Steffen, W. L. and Walker, B. H., 1995. Terrestrial transects for global change research. Vegetatio 121(1-2), pp. 53-65.

MacArthur, R. H., 1969. Patterns of communities in the tropics. Biological Journal of the Linnean Society 1(2), pp. 19-30.

Menzel, A., Sparks, T. H., Estrella, N., Koch, E., Aasa, A., Ahas, R., Alm-Kübler, K., Bissolli, P., Braslavská, O., Briede, A., Chmielewski, F. M., Crepinsek, Z., Curnel, Y., Dahl, A. s., Defila, C., Donnelly, A., Filella, Y., Jatczak, K., Må ge, F., Mestre, A., Nordli, O. y., Peñuelas, J., Pirinen, P., Remišová, V., Scheifinger, H., Striz, M., Susnik, A., Van Vliet, A. J. H., Wielgolaski, F.-E., Zach, S. and Zust, A., 2006. European phenological response to climate change matches the warming pattern. Global Change Biology 12(10), pp. 1969-1976.
Oosterbaan, R., Sharma, D., Singh, K. and Rao, K., 1990. Crop production and soil salinity: evaluation of field data from India by segmented linear regression with breakpoint. Proceedings of the symposium on land drainage for salinity control in arid and semiarid regions 3, pp. 1-12.

Running, S. W. and Hunt, E. R., 1993. Generalization of a forest ecosystem process model for other biomes, BIOME-BGC, and an application for global-scale models. In: J. R. Ehleringer and C. B. Field (eds), Scaling physiological processes leaf to globe, Academic Press, chapter 8, pp. 141-158.

Running, S. W., Justice, C. O., Salomonson, V., Hall, D., Barker, J., Kaufmann, Y. J., Strahler, A. H., Huete, A. R., Muller, J. P., Vanderbilt, V., Wan, Z. M., Teillet, P. and Carneggie, D., 1994. Terrestrial remote sensing science and algorithms planned for EOS/MODIS. International Journal of Remote Sensing 15(17), pp. 35873620 .

Schwartz, M. D., 1999. Surface phenology and satellite sensor-derived onset of greenness: an initial comparison. International Journal of Remote Sensing.

Sellers, P. J., Randall, D. A., Collatz, G. J., Berry, J. A., Field, C. B., Dazlich, D. A., Zhang, C., Collelo, G. D. and Bounoua, L., 1996. A revised land surface parameterization $(\mathrm{SiB} 2)$ for atmospheric GCMs .1. Model formulation. Journal of Climate 9(4), pp. 676-705.

Sparks, T. H. and Jeffree, E. P., 2000. An examination of the relationship between flowering times and temperature at the national scale using long-term phenological records from the UK. International Journal of ....

Stöckli, R., 2004. European plant phenology and climate as seen in a 20-year AVHRR land-surface parameter dataset. International Journal of Remote Sensing.

Waring, R. H., Milner, K. S., Jolly, W. M., Phillips, L. and McWethy, D., 2006. Assessment of site index and forest growth capacity across the Pacific and Inland Northwest U.S.A. with a MODIS satellite-derived vegetation index. Forest Ecology and Management 228(1-3), pp. 285-291.

Wayne Skaggs, R., 1996. Drainage principles and applications. Agricultural Water Management 31(3), pp. 307-309.

White, M. A. and Thornton, P. E., 1997. A continental phenology model for monitoring vegetation responses to interannual climatic variability. Global ....

Williams, R. J., Duff, G. A., Bowman, D. M. J. S. and Cook, G. D., 1996. Variation in the composition and structure of tropical savannas as a function of rainfall and soil texture along a large-scale climatic gradient in the Northern Territory, Australia. Journal of Biogeography 23(6), pp. 747-756.

Zhang, X. Y., Friedl, M. A., Schaaf, C. B., Strahler, A. H., Hodges, J. C. F., Gao, F., Reed, B. C. and Huete, A., 2003. Monitoring vegetation phenology using MODIS. Remote Sensing of Environment 84(3), pp. $471-475$. 